\title{
Development of Home Network Sustainable Interface Tools
}

\author{
Erman Hamid $^{1}$, Nazrulazhar Bahaman ${ }^{2}$, Azizah Jaafar ${ }^{3}$, Ang Mei Choo ${ }^{4}$, Akhdiat Abdul Malek ${ }^{5}$ \\ Universiti Teknikal Malaysia Melaka, Hang Tuah Jaya, 76100 Durian Tunggal, Melaka, Malaysia ${ }^{1,2}$ \\ Institute of Visual Informatics, Universiti Kebangsaan Malaysia, 43600 UKM Bangi, Selangor, Malaysia ${ }^{3,4}$ \\ Faculty of Major Language Studies, Universiti Sains Islam Malaysia, Bandar Baru Nilai 72800 Nilai, Negeri Sembilan, Malaysia ${ }^{5}$
}

\begin{abstract}
The home network has become a norm in today's life. Previous studies have shown that home network management is a problem for users who are not in the field of network technology. The existing network management tools are far too difficult to understand by ordinary home network users. Its interface is complex, and does not address the home user's needs in their daily use. This paper presents an interactive network management tool, which emphasizes support features for home network users. The tool combine interactive visual appearance with persuasive approach that support sustainability. It is not only understandable to all categories of home network users, but also acts as a feature for the user to achieve usability.
\end{abstract}

Keywords—Home network; visualization; sustainable interface

\section{INTRODUCTION}

Computer network refers to unlimited connection that enables resource sharing [1]. It becomes increasingly important, as the world is moving towards globalization [2]. It means that everything is free to be accessed from anywhere at any time.

In line with the rapid development of network technology, home network becomes more important [3]. It is firmly known that network technology is now a must in every home [4]. The usage of network at home has become widespread, causing a nature of using network technology in every activity including entertainment, working from home, and collaborative learning.

The fast-growth of home network however contributed to the problem of home network user. Not all of them are knowledgeable in network and technology, and this caused some sort of home network management problems [4]. The problems involve hardware and software failure, connectivity or security problems [5]. These ultimately affect the usability of home network, causing the need of assistant roles that could help all types of users of network at home.

Network management has become important and a must in household tasks as the home network become essential part of people's life [4][6][7]. There are too many tasks that home network user need to know in using their network including setting up the infrastructure of the network, connecting to the internet, and managing the quality and security of the network [4][8][9]. All of these needs to be done with ample technical knowledge in network technology and not all of the home network users possess the knowledge.

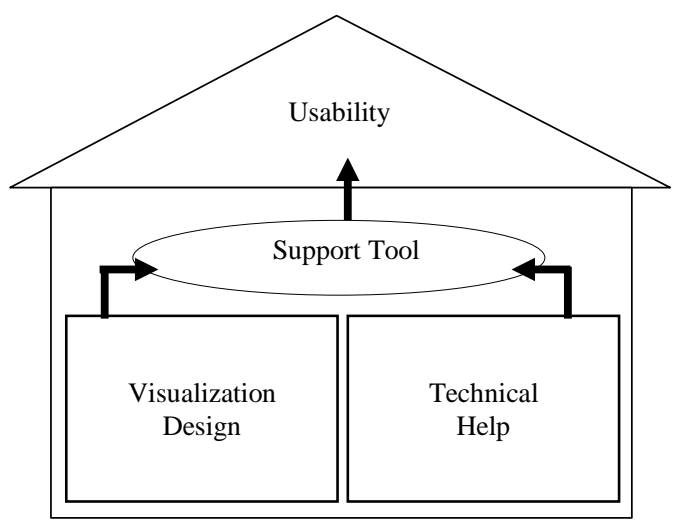

Fig. 1. A Support Tool for Home Network user.

It is now a norm, when home network users feel lost while using their home network [4][8][9]. It may be that their connection is disconnected, they do not know what is happening and do not even know how to correct the problem [10][11][12][13]. It could be that the network speed is too slow, and they keep using the network without knowing that something could be done to increase the network speed [11][12]. It also might be their network is interfered by unwanted invaders but they do not even know that their network is compromised [13].

From the previous researches, it appears that the users of home network shall have something that look like as an assistant in facilitating their use. The assistant may act as a facilitator that always available when needed, guiding the user in handling their network management problem, and be helpful in delivering helps in the way the user can understand. It shall feature in supportive interface and helps users in managing their network (as shown in Fig. 1) to finally achieve usability.

\section{Methodology}

As stated earlier, the key challenge in this research is providing an interface that could act as an assistant to home network users. The previous study drives to introducing a better way of visualizing the interface of home network support tool. It should accompanied with a right way in persuading user understanding, to make users feel assisted when dealing with their network. This can affect the user's level of sustainability in the use of home networks, thus helping them in achieving usability. Research then begin with defining the needs of home network users, and proceed with the development of the sustainable interface simulation prototype. 


\section{A. Understandings Home Network Needs}

The first step is to understand the needs of home network users in order to achieve usability. These are so important to ensure that the tools developed can perfectly meet the user's need in assisting them while using their network. It is important to understand the users, to finally design the interface specifically to the scope needed.

Field observation technique which is popular and widely used on previous research has been chosen. The work started with ethnographic observation in order to get credible samples [14][13]. From that, we proceed to the field observation study that allows us to find out the clear opinion relating to what actually happened in Home Network [5]. They are given scenarios with existing home network management tools, observed, evaluated, and interviewed briefly to confirm the data gathered from the observation session [12][15]. Fig. 2 shows the steps taken in order to understand the home network needs.

It is clear that the previously conducted literacy studies provide the same answers as the field studies of this research. The problems of home network users focus around the lack of technical aspects of network user and the absence of homenetworking support tools that are suitable for them [16]. The home network users really need a tool as a helper in order to guide them in using their home network [15]. For this purpose, a home networking support tool with appropriate interface can be developed. It needs to provide clear message, reliable, well functioned and has attractive visualization as shown in Fig. 3.

\section{B. Sustainable Interface Concept and Simulation Prototype}

A good interface can be more effective with a touch of sustainability [17]. It would exactly provide an improved tool with meaningful touches that makes them more helpful [18]. The interface that focuses on the nature of visualizing including picturing, understanding, explaining and memorizing [19][20][21]; can be more effective with the injection of persuasive elements [22]. It seems like an injection of driving elements, persuasion, guidance and influence in to the visual interface can be done in order to assist user understandings $[22][23][24][25]$. Both of these visualization and persuasive elements can be coordinated into an interface of home network support tool that is capable to meet the usability of home networking. The concepts of sustainable visualization interface in the home network support tools are shown in Fig. 4.

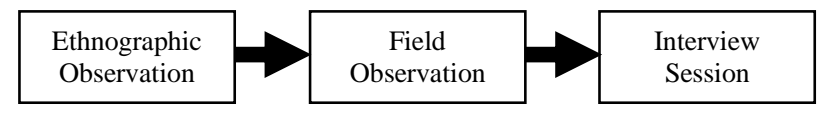

Fig. 2. Data Gathering Technique.

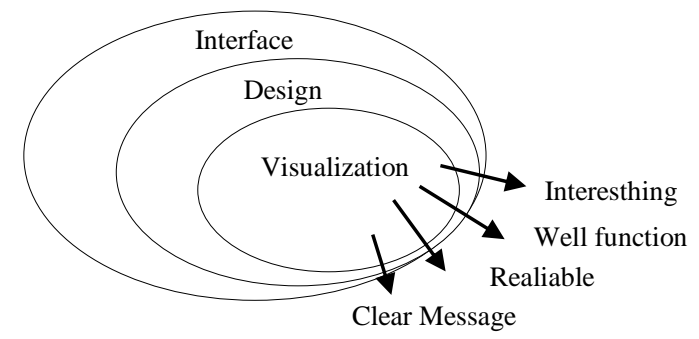

Fig. 3. Relation between Interface, Design and Visualization.

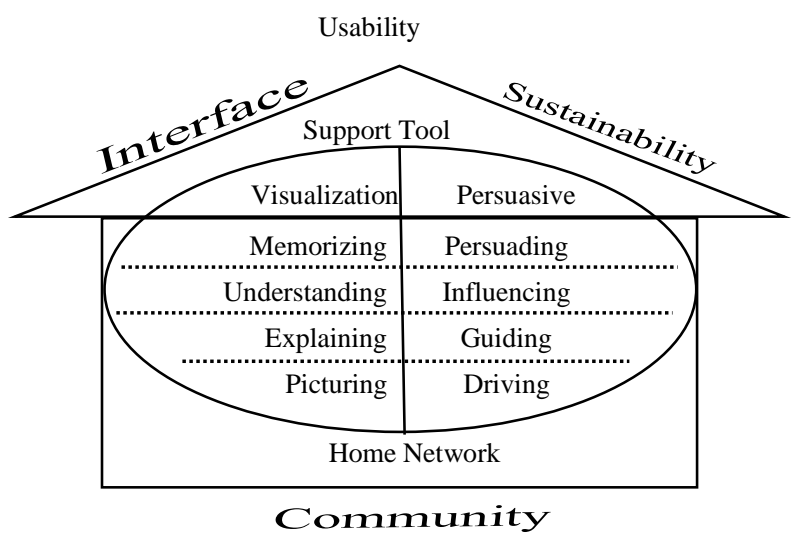

Fig. 4. Sustainable Interface Concept.

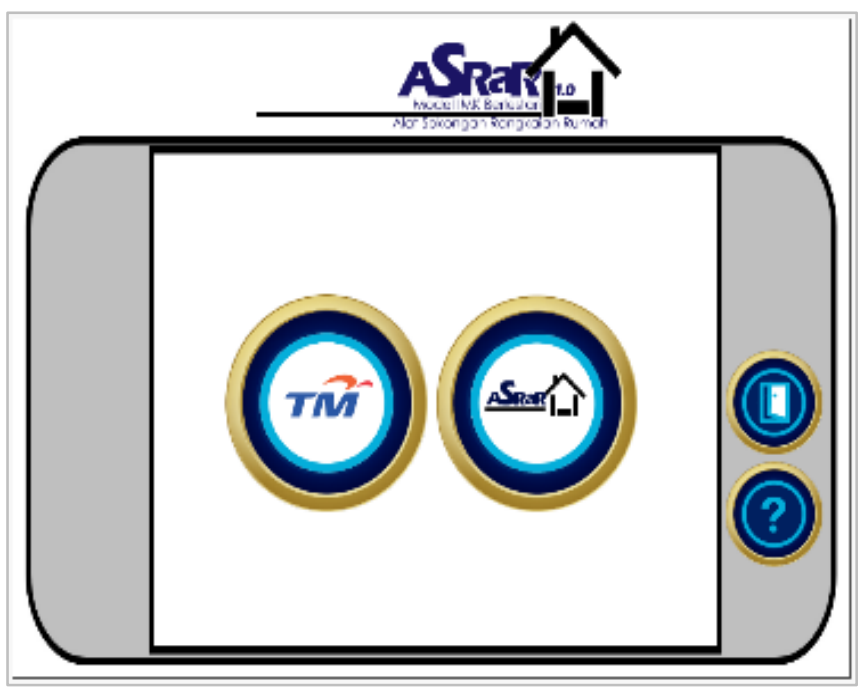

Fig. 5. The Entrance Interface of ASRaR.

Next, the interface of home network support tool is designed based on visualization and persuasive features. It should act as the helper for the home network user to achieve usability. It is developed in the form of a prototype simulation, with an interface that includes the scenario of computer networking behavior. It is just like the user is using the tool in real condition, focusing on the extent to which the user can interact with the prototype simulator interface. The prototype simulation is named as ASRaR (refer Fig. 5) which summarized from Malay-language terms called Home Network Support Tools (Alatan Sokongan Rangkaian Rumah).

\section{Sustainable Interface Concept and Simulation Prototype}

To gather feedback on ASRaR, a basic evaluation phase was performed with the same 15 participants that used in the preliminary research (requirements gathering phase). The participants came from three categories of users; expert (technically expert), intermediate (technology knowledgeable), and novice (less technical knowledge) as shown in Table 1. They were given scenarios with ASRaR, observed and evaluated, and followed by a brief interview to get their views on the ASRaR interface. The interviews were done to confirm the data gathered from the observation session. 
TABLE I. PARTICIPANT DETAILS

\begin{tabular}{|c|c|}
\hline Identity & Background \\
\hline P1 & $\begin{array}{l}\text { Intermediate: Students of banking study. Able to use } \\
\text { computers, and know basic in dealing with computer network } \\
\text { problems. }\end{array}$ \\
\hline $\mathrm{P} 2$ & $\begin{array}{l}\text { Intermediate: Student of secretarial study. Waiting for college } \\
\text { offers at the data gathering stages, and spent a lot of time on the } \\
\text { Internet. }\end{array}$ \\
\hline P3 & $\begin{array}{l}\text { Novice: A full-time housewife. Occasionally use the Internet to } \\
\text { connect with children's and friends. }\end{array}$ \\
\hline P4 & $\begin{array}{l}\text { Novice: Students of accounting study. Worked for } 10 \text { years, } \\
\text { then quit to become a full-time housewife. Almost every day } \\
\text { using the internet through smartphones. }\end{array}$ \\
\hline P5 & $\begin{array}{l}\text { Novice: Work as Hostel Assistant. Have a very basic knowledge } \\
\text { on computers and the Internet. }\end{array}$ \\
\hline P6 & $\begin{array}{l}\text { Novice. A Policeman. Love trying out new things on the } \\
\text { Internet. Use internet more on smartphones than computers. }\end{array}$ \\
\hline P7 & $\begin{array}{l}\text { Intermediate: An insurance and direct-selling agent. Use the } \\
\text { Internet most in his career. }\end{array}$ \\
\hline P8 & Intermediate: English teacher that very good in technologies. \\
\hline P9 & $\begin{array}{l}\text { Intermediate: Creative media lecturer that who are literate in } \\
\text { computer networking. }\end{array}$ \\
\hline $\mathrm{P} 10$ & $\begin{array}{l}\text { Expert: Senior Lecturer of computer networking. Very expert in } \\
\text { network technology. }\end{array}$ \\
\hline P11 & $\begin{array}{l}\text { Novice: A religious Teacher. Know basic things regarding } \\
\text { internet. }\end{array}$ \\
\hline $\mathrm{P} 12$ & $\begin{array}{l}\text { Novice: A full-time housewife. Poor in technology, but uses } \\
\text { Android application rigidly. }\end{array}$ \\
\hline $\mathrm{P} 13$ & $\begin{array}{l}\text { Novice: Twenty years' experience in architecture field. Expert } \\
\text { in application regarding architecture, but that's all. }\end{array}$ \\
\hline $\mathrm{P} 14$ & $\begin{array}{l}\text { Intermediate: Student of engineering study. Able to use } \\
\text { computer and network basically. }\end{array}$ \\
\hline P15 & $\begin{array}{l}\text { Intermediate: A Technical Assistant of engineering field. } \\
\text { Know basic about computer and networking. }\end{array}$ \\
\hline
\end{tabular}

\section{RESULT AND DISCUSSION}

Based on the literature review and the preliminary study results, a fully functional simulation prototype of ASRaR is created. It included with overall interface design with sustainable visualization elements suggested by the result of preliminary study. The discussion then goes on the development of the interface. It then focuses on the implementation of the system, and the approach in allowing the interface to help user of home network in achieving usability.

\section{A. The ASRaR's Flow}

The interface starts with front window with two options; a link to the main window and a link to the internet service provider's portal (http://192.168.1.1). There are choice to bring users to the main interface screen. The interface further supplies four functional options with one help option. The functions consist of an account management, connectivity, monitoring, and control. Each function has a return link to the main interface as shown in Fig. 6.

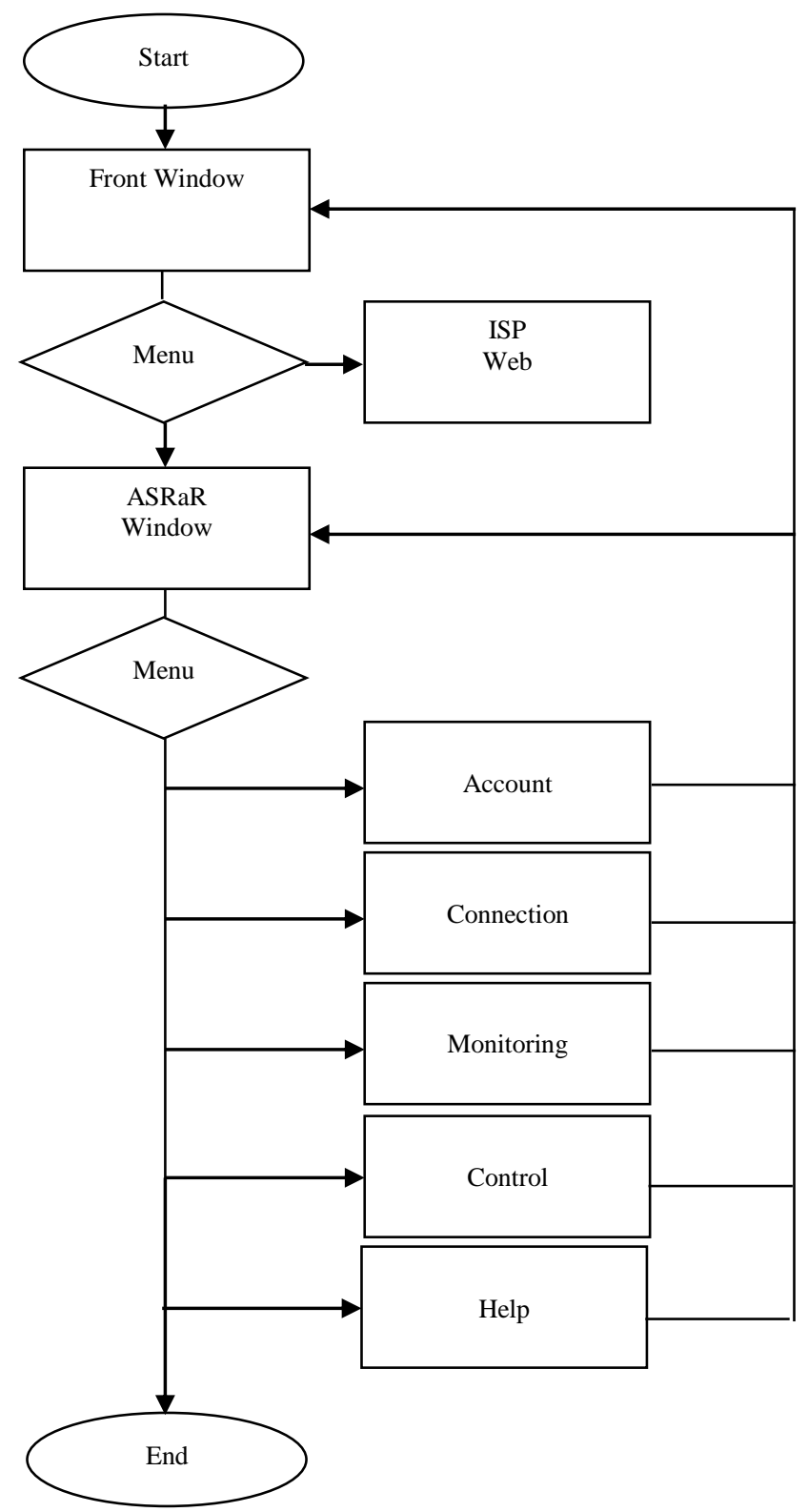

Fig. 6. The Flow Chart of ASRaR.

\section{B. Support $=$ Visual + Persuasive}

Literature review and preliminary study stated that managing the account of home network could cause problems for users with less technical knowledge. Existing network management tools are too technical to be understood by normal home users. As a solution, ASRaR comes up with a clear and helpful interface representation. It is based on problem-solving method, with the coordination of visual and persuasive approaches. The visual display are designed with a viewing and explaining approach, which aims to gain more user understandings. It is enriched by the persuasive interactions; with the concept of asking and suggesting, which encourages to provide assistance for user. It complemented each other when visual display accompanied by persuasive interaction targeted to establish a capable support tool to achieve usability. The coordination of visual and persuasive elements in the interface is shown in Fig. 7. 


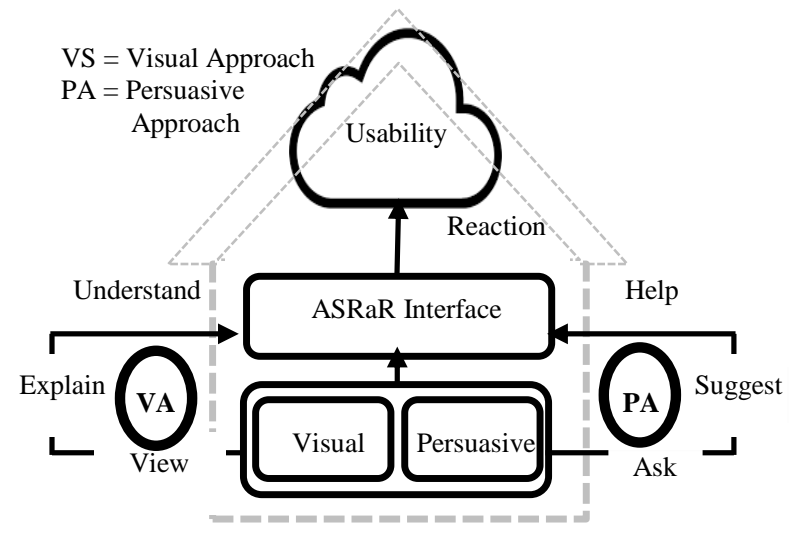

Fig. 7. The Interaction of Visual, Persuasive, Support and Usability.

\section{Account Management}

Account Management is an important mechanism in every information system including home network. For this, the interface includes features in account management to enable users to control their own home network. This feature allows users to register their membership in the home network and view their own account in their screen.

\section{Troubleshooting Network Connection}

Troubleshooting is another important feature that aims to help users troubleshoot specific issues in their network. The interface provides ability to check for non-functioning router issues. Potential problems of router is displayed, and the interface recommends the answer. The interaction then describes the solution of the problem, helping users solve their problem.

\section{E. Monitoring Network Traffic}

The next feature is to display a network topology showing the terminals that are currently connected to the network. As shown in Fig. 8, the network is displayed in a tree diagram that shows the actively connected host to the network. By this feature, users can know if there are any unwanted users connected in their network. This features allows users to see the identity of connected user and their activity.

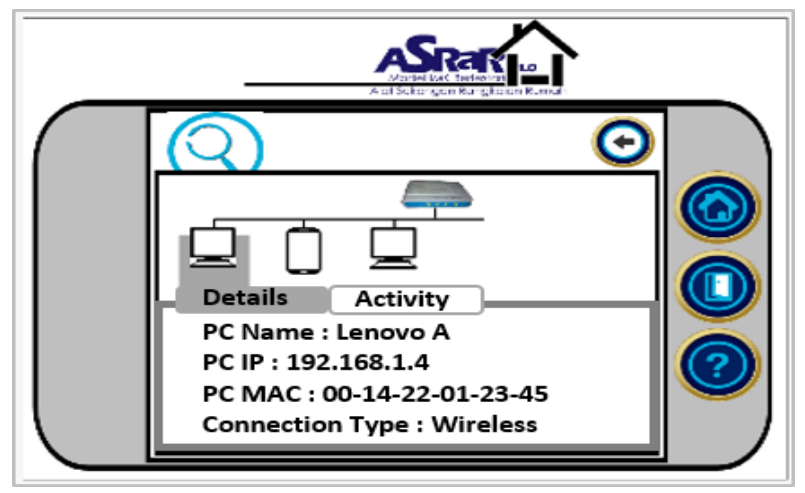

Fig. 8. The Monitoring Interface of ASRaR.

\section{F. Managing Network}

Account management is the task associated with detecting the new devices that go into the network. The interface gives the ability to do the parental management, in order to ensure safe access by under-age users. The interface also includes the feature to kick any connected user out of the network.

As explained in the introduction to this paper, the goals of ASRaR were not merely to design the interface for home network management tool, but also to get the feedback from users. There are, however, a number of challenges inherent in getting the users' feedback. Because it is a simulation prototype, users need to be explained that ASRaR is a simulation of home networking tools and it represents the scenario that has been developed. Users should be told that they are required to use ASRaR, and then interviewed.

\section{G. Analysis}

A brief interview session was conducted after the testing session, specifically with two basic questions; (i) the level of acceptance of the interface, (ii) the influence of ASRaR on the Home Network:

Question (i): Is the ASRaR interface user friendly to you? Why?

93\% of respondents agreed that the ASRaR interface is easy to understand. They feel that the visual display is not complex and very helpful to users. It is very direct, with button that give adequate interaction to help them when using ASRaR.

Question (ii): Home Network becomes easier after using ASRaR, your opinion?

$86 \%$ of respondents agreed that ASRaR is able to make the home network easier. On average they are happy with the way ASRaR projects the choice of network troubleshooting, and like the features of monitoring and network management.

\section{CONCLUSION}

This research have explored the challenges of proposing a new interface for home networking. It features visualization and persuasive coordination, which forms a home networking support tool aimed to achieve usability. ASRaR provides a range of mechanisms for supporting home network management, with intention of being an assistant for home users for all time needed. While the evaluation demonstrates the acceptance of the system, ASRaR can be further developed from a simulation prototype to a fully completed system. It could definitely replace the existing ISP's tool that came along with the internet service that is rented from the ISPs.

\section{ACKNOWLEDGMENT}

The authors would like to thank C-ACT and INSFORNET Research Group of Universiti Teknikal Malaysia Melaka (UTeM) for providing facilities and financial support under the university Short Term Grant with Project No. PJP/2018/FTMK(4b)/S01631. 


\section{REFERENCES}

[1] Aeri and S. Tukadiya, "A comparative study of network based system log management tools," 2015 Int. Conf. Comput. Commun. Informatics, pp. 1-6, 2015. doi: 10.1109/ICCCI.2015.7218075.

[2] A. Moallem, "Why should home networking be complicated?," in Advances in Usability Evaluation: Part II, CRC Press, pp. 4169-4178, 2013.

[3] N. Castelli, C. Ogonowski, T. Jakobi, M. Stein, G. Stevens, and V. Wulf, "What Happened in my Home?: An End-User Development Approach for Smart Home Data Visualization," in 2017 CHI Conference on Human Factors in Computing Systems, 2017, pp. 853-866. doi: $10.1145 / 3025453.3025485$.

[4] M. Chetty and N. Feamster, "Refactoring Network Infrastructure to Improve Manageability: A Case Study of Home Networking," ACM SIGCOMM Comput. Commun. Rev., vol. 42, no. 3, pp. 54-61, 2012.

[5] J. Yang, W. Edwards, and D. Haslem, "Eden: supporting home network management through interactive visual tools," Proc. 23nd Annu. ACM Symp. User interface Softw. Technol. ACM., pp. 109-118, 2010. doi: 10.1145/1866029.1866049.

[6] R. E. Grinter et al., "The ins and outs of home networking," ACM Trans. Comput. Interact., vol. 16, no. 2, pp. 1-28, Jun. 2009.

[7] P. Tolmie, A. Crabtree, and T. Rodden, "Making the home network at home: Digital housekeeping," ECSCW 2007. Springer London., no. September, p. 331-350., 2007.

[8] R. Mortier et al., "Control and understanding: Owning your home network," 2012 Fourth Int. Conf. Commun. Syst. Networks (COMSNETS 2012), pp. 1-10, Jan. 2012. doi: 10.1109/COMSNETS.2012.6151322.

[9] P. Brundell, A. Crabtree, R. Mortier, T. Rodden, P. Tennent, and P. Tolmie, "The network from above and below," Proc. first ACM SIGCOMM Work. Meas. up stack - W-MUST '11, p. 1, 2011. doi: 10.1145/2018602.2018604.

[10] M. Chetty, D. Haslem, and A. Baird, "Why is my internet slow?: making network speeds visible," Proc. SIGCHI Conf. Hum. Factors Comput. Syst. ACM., pp. 1889-1898, 2011. doi: 10.1145/1978942.1979217.

[11] E. Poole and M. Chetty, "More than meets the eye: transforming the user experience of home network management," Proc. 7th ACM Conf. Des. Interact. Syst. ACM., pp. 455-464, 2008. doi: 10.1145/1394445.1394494.

[12] A. Crabtree, R. Mortier, T. Rodden, and P. Tolmie, "Unremarkable networking: the home network as a part of everyday life," Proc. Des. Interact. Syst. Conf. ACM., pp. 554-563, 2012. doi: 10.1145/2317956.2318039.
[13] E. Poole, M. Chetty, and T. Morgan, "Computer help at home: methods and motivations for informal technical support," Proc. SIGCHI Conf. Hum. Factors Comput. Syst. ACM., pp. 739-748, 2009. doi: 10.1145/1518701.1518816.

[14] S. Bly, B. Schilit, and D. McDonald, "Broken expectations in the digital home," CHI'06 Ext. Abstr. Hum. factors Comput. Syst. ACM.. ACM., pp. 568-573, 2006. doi: 10.1145/1125451.1125571.

[15] R. E. Grinter, W. K. Edwards, M. W. Newman, and N. Ducheneaut, "The Work to Make a Home Network Work," Ecscw 2005, vol. 200, no. September, pp. 469-488, 2005.

[16] K. Xu, X. Wang, W. Wei, H. Song, and B. Mao, "Toward software defined smart home," IEEE Commun. Mag., vol. 54, no. 5, pp. 116-122, 2016.

[17] P. H. Raven, "Science, sustainability, and the human prospect," Science (80-. )., vol. 297, no. 5583, pp. 954-958, 2002.

[18] C. Midden, T. Mccalley, J. Ham, and R. Zaalberg, "Using persuasive technology to encourage sustainable behavior," Work. Pap. 6th Int. Conf. Pervasive Comput., no. 1, pp. 83-86, 2008.

[19] D. Chen and B. Li, "A product visualization model construction method in Computer Aided Conceptual Design," 2010 IEEE 11th Int. Conf. Comput. Ind. Des. Concept. Des. 1, vol. 1, pp. 185-190, 2010. doi: 10.1109/CAIDCD.2010.5681378.

[20] D. W. H. Ten, S. Manickam, S. Ramadass, and H. a. Al Bazar, "Study on Advanced Visualization Tools In Network Monitoring Platform," 2009 Third UKSim Eur. Symp. Comput. Model. Simul., pp. 445-449, 2009.

[21] R. Lintern, J. Michaud, M. Storey, and X. Wu, "Plugging-in visualization: experiences integrating a visualization tool with Eclipse," Proceedings of the 1st ACM symposium on Software visuallization, pp. 47-57, 2003. doi: 10.1145/774833.774840.

[22] E. M. Huang, E. Blevis, J. Mankoff, L. P. Nathan, and B. Tomlinson, "Defining the role of HCI in the challenges of sustainability," Proc. 27th Int. Conf. Ext. Abstr. Hum. factors Comput. Syst. - CHI EA '09, p. 4827, 2009. doi: 10.1145/1520340.1520751.

[23] B. Knowles, L. Blair, P. Coulton, and M. Lochrie, "Rethinking plan A for sustainable HCI," Proc. 32nd Annu. ACM Conf. Hum. factors Comput. Syst. - CHI '14, pp. 3593-3596, 2014. doi: $10.1145 / 2556288.2557311$.

[24] R. Chowdhury, N. M., \& Boutaba, "A survey of network virtualization," Comput. Networks, vol. 54, no. 5, pp. 862-876, 2014.

[25] E. Paulos, M. Foth, C. Satchell, Y. Kim, P. Dourish, and J. H. Choi, "Ubiquitous Sustainability: Citizen Science \& Activism (Workshop)," in Proceedings of the 10th international conference on Ubiquitous computing (Ubicomp '08), 2008, no. 2008. 